\title{
Caso clínico radiológico adultos
}

EDUARDO SABBAGH P.*, MÓNICA ANTOLINI T.*, FABIOLA SALAZAR M.* y ANDRÉS MORENO G.**

\section{Antecedentes Clínicos}

Hombre de 61 años portador de insuficiencia renal crónica. Trasplante renal donante cadáver año 1982. Presenta rechazo crónico y vuelve a hemodiálisis convencional en 2003. Portador de osteodistrofia renal severa y estenosis aórtica severa. Se le solicita Rx de tórax para control de rutina en paciente trasplantado y luego TAC de Tórax en 2007. Asintomático hasta enero de 2010 cuando empieza con disnea progresiva por lo que se solicita nueva TAC de tórax. A continuación, se presentan imágenes de ambas tomografías.
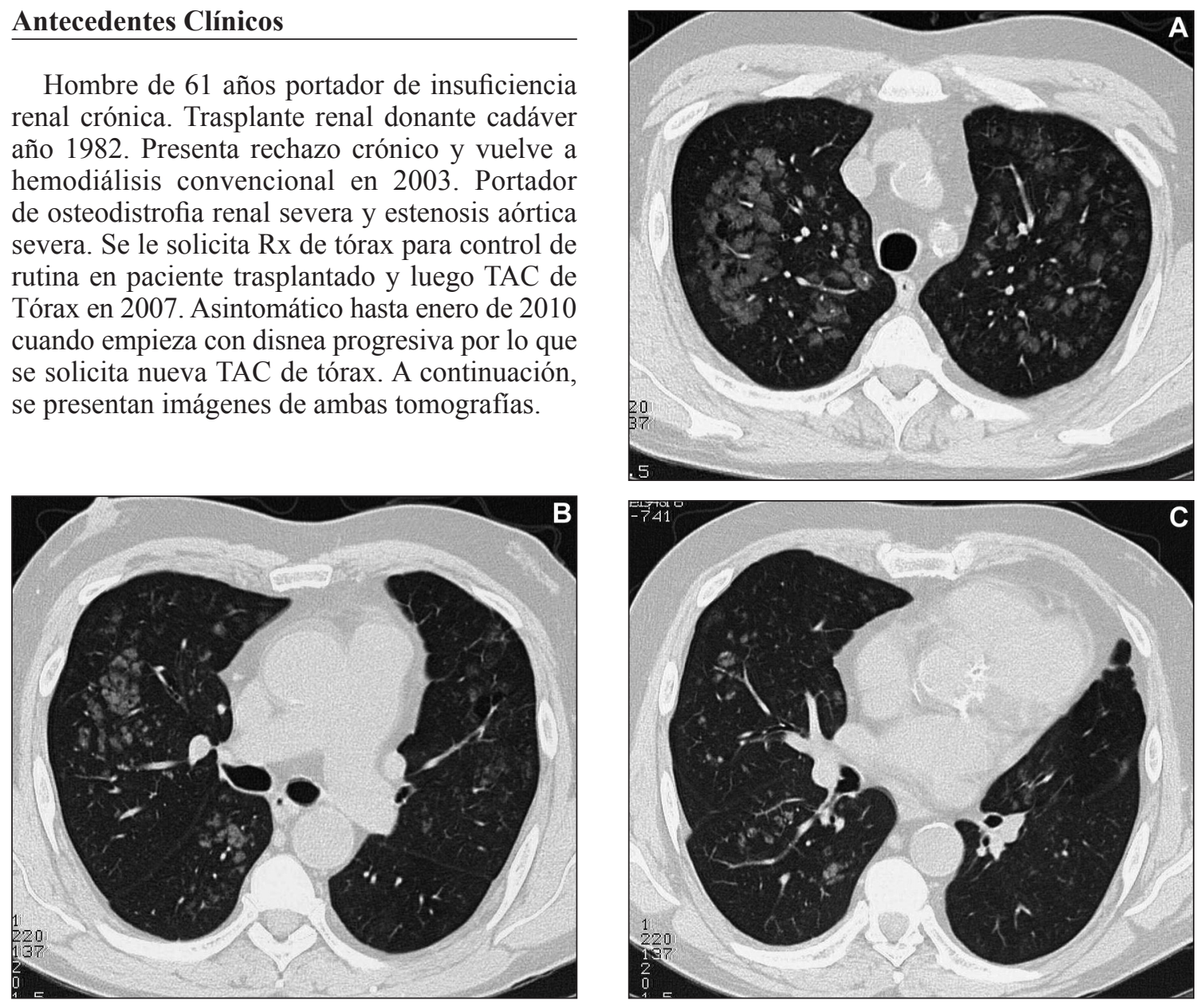

Figura 1. (A, B y C): Tomografía axial computada (TAC) efectuada en abril de 2007.

Describa las imágenes y plantee un diagnóstico.

\footnotetext{
* Servicio de Radiología. Instituto Nacional del Tórax. Santiago de Chile.

** Hospital Clínico San Borja-Arriarán. Santiago, Chile.
} 

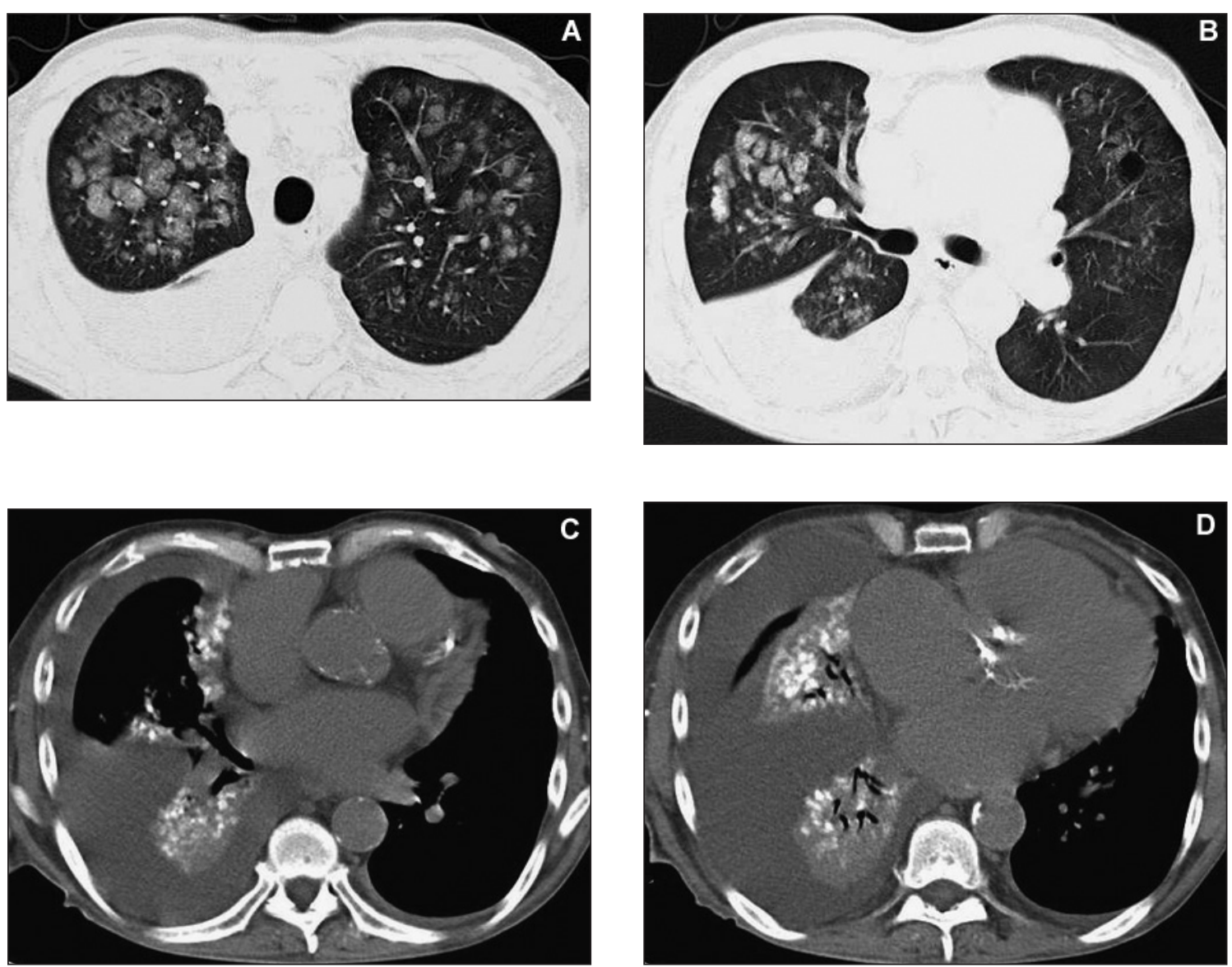

Figura 2. (A, B, C y D): Tomografía axial computada de tórax efectuada en Febrero 2010.

\section{Descripción radiológica}

Las tomografías correspondientes a la Figura 1 (A, B y C), de abril del año 2007, demuestran una enfermedad pulmonar difusa, de predominio superior, central, caracterizada por tenues opacidades centro lobulillares, con aspecto en "roseta", donde cada uno de sus componentes refleja la forma de un acino. O sea, corresponde a un aumento heterogéneo de la densidad centro acinar.

Posteriormente en enero del 2010, la Figura 2 (A y B), muestra las mismas alteraciones, pero claramente de mayor densidad. Así, con técnica de tejidos blandos, Figura 2 (C y D), se puede apreciar que corresponde a densidad cálcica.

Adicionalmente, se observa derrame pleural bilateral, leve en el lado izquierdo y abundante en el derecho, con atelectasia pasiva del parénquima. El corazón está aumentado de tamaño y hay calcificaciones coronarias, en la válvula aórtica y aorta.

\section{Discusión}

Las imágenes descritas demuestran un proceso centro acinar, o sea que tiene que ver con los ejes broncovasculares y por lo tanto la etiopatogenia está relacionada con esas estructuras. Así, se pueden considerar patologías como alveolitis alérgica extrínseca, procesos infecciosos, sarcoidosis, y procesos linfoproliferativos, etc. En este paciente existe además una característica distintiva, que es el depósito paulatino de calcio.

El depósito de calcio en el pulmón puede ser localizado o difuso, siendo el primero lo más frecuente y en general relacionado a procesos granulomatosos.

Las calcificaciones difusas del parénquima pulmonar son muy poco frecuentes, entre ellas tenemos a la amiloidosis, que consiste en depósitos de amiloide que se pueden calcificar, pero en general en forma de nódulos e incluso masas heterogéneas, parcialmente confluentes 
y muy extensas, que se relacionan con el tejido conectivo linfático, pudiendo ser centro acinares y corticales subpleurales. Otra calcificación difusa es la microlitiasis, donde el proceso es predominantemente alveolar y por lo tanto son calcificaciones que suelen afectar más hacia la corteza, donde hay mayor número de alvéolos, en forma de finos micro nódulos como granos de arena, de predominio basal. La Varicela, también puede producir calcificación difusa, pero también es de predominio basal y en forma de nódulos mayores que pueden alcanzar hasta $5 \mathrm{~mm}$, y relativamente aislados. Otra causa de depósito de calcio es el presente en hiperparatiroidismo secundario a insuficiencia renal crónica, llamada calcificación metastásica del pulmón, condición mucho más frecuente de lo diagnosticado, ya que habitualmente es tenue y no es visible en la radiología, pero está presente en pruebas bioquímicas en la biopsia. Esta es una condición que se da en pacientes con alteraciones del metabolismo del calcio y fósforo, siendo más común de encontrar en la insuficiencia renal crónica terminal, pero también se da en hiperparatiroidismo primario.

El depósito de calcio ocurre de preferencia en tejidos donde existe excreción de ácidos, como el estómago, riñón y pulmón, donde precipita en pequeños vasos de la membrana alveolar y en tejidos blandos.

En el pulmón se deposita preferentemente en zonas apicales, dado el $\mathrm{pH}$ alcalino presente en esta zona que favorece la precipitación cálcica.

Esta condición no tiene un cuadro clínico especifico, lo que favorece el subdiagnóstico. Usualmente es asintomático y tiene un curso benigno. Algunos síntomas relacionados son: alteraciones del estado anímico, dolores óseos generalizados, síndrome ulceroso, polidipsia y poliuria. En algunos casos puede desarrollar falla respiratoria fulminante.

La radiografía de tórax puede mostrar suaves calcificaciones de los vasos arteriales, pero carecen de especificidad y sensibilidad con respecto a la identificación de la calcificación metastática. La TAC de tórax es muy sensible en la detección de focos calcificados. Los patrones radiológicos descritos en la literatura son:
- Múltiples nódulos calcificados difusos distribuidos en todo el pulmón y predominantemente en los ápices.

- Areas en vidrio esmerilado difusas o en parche, o consolidación.

- Consolidación confluente de parénquima de alta atenuación, con distribución lobar imitando neumonía lobar.

Además se describen calcificaciones en pared bronquial, miocardio y dentro de los vasos de la pared torácica.

Finalmente la cintigrafía ósea es el método de mayor ayuda para detectar calcificación metastásica.

Nuestro paciente cumple con las características de este cuadro de calcificación metastásica del pulmón tanto clínico como radiológico. Insuficiencia renal crónica, compromiso centro acinar difuso de predominio superior, que va empeorando con los años. El derrame pleural bilateral asociado es atribuible a descompensación de insuficiencia cardíaca secundaria a estenosis aórtica de base.

\section{Bibliografías}

1.- CASTILLO M C, GIMENO M J, CARRO B. Calcinosis pulmonar difusa en paciente con insuficiencia renal. Arch Bronconeumol 2005; 41 (10): 587- 9.

2.- KF TAM, K WANG, WC FAN. Metastatic calcification 186. J HK Coll Radiol 2002; 5: 186-9.

3.- KANG, et al. Atypical radiologic manifestation of pulmonary metastatic calcification. Korean J Radiol 2008; 9 (2).

4.- LINGAM R K, TEH J, SHARMA A, FRIEDMAN E. Metastatic pulmonary calcification in renal failure: a new HRCT pattern. Br J Radiol 2002; 75: 74-7.

5.- HARTMAN T E, MULLER N, PRIMACK S L, et al. Metastatic pulmonary calcification in patients with hypercalcaemia: findings on chest radiographs and CT scans. AJR 1994; 162: 799-802.

6.- BROWN K, MUND D F, ABERLE D R, BATRA P, YOUNG D A, et al. Intrathoracic calcifications: radiographic features and differential diagnoses. Radiographics 1994; 14: 1247-61.

Correspondencia a:

Dr. Eduardo Sabbagh P.

Servicio de Radiología.

Instituto Nacional del Tórax.

E-mail: edo.sabbagh.p@vtr.net 